\title{
PREIMPLANTATION GENETIC TESTING Chromosome abnormalities in human embryos
}

\author{
Carmen Rubio', Lorena Rodrigo ${ }^{2}$ and Carlos Simón $3,4,5,6$ \\ ${ }^{1} R \& D$ Department, Igenomix \& INCLIVA, Valencia, Spain, ${ }^{2}$ PGT-A Department, Valencia, Spain, ${ }^{3}$ University of \\ Valencia, Valencia, Spain, ${ }^{4}$ BIDMC Harvard University, Boston, Massachusetts, USA, ${ }^{5}$ Baylor College of Medicine, \\ Houston, Texas, USA and ${ }^{6}$ Igenomix, Valencia, Spain \\ Correspondence should be addressed to C Rubio; Email: carmen.rubio@igenomix.com
}

This paper forms part of an anniversary issue on Preimplantation Genetic Testing. The guest editor for this section was Professor Alan Handyside, School of Biosciences, University of Kent, Canterbury, UK.

\begin{abstract}
Aneuploidy is a frequent event in human embryos, and its incidence is higher in oocytes and embryos from women of advanced maternal age. Aneuploidy may also be a contributing factor in infertile populations, such as couples with recurrent miscarriages, repetitive implantation failure, or male infertility. For these reasons, preimplantation genetic testing for aneuploidy (PGT-A) has been proposed to prevent miscarriages and increase live birth rates in infertile couples undergoing in vitro fertilisation. Next-generation sequencing is currently being applied for the detection of aneuploidies in human embryos, including whole chromosome aneuploidies, segmental aneuploidies, uniform, and mosaic aneuploidies. More recently, this technology has been incorporated for the analysis of the cell-free DNA secreted by the embryo to the culture media. Chromosome abnormalities mostly originate in female meiosis. Recombination between homologous chromosomes is a critical event that occurs in the foetal ovary. The importance of altered recombination pertains to paternally as well as maternally derived trisomies, but as most aneuploidy arises during oogenesis, the female is at greater risk. For males, sperm concentration is associated with a higher risk of aneuploid sperm and thus aneuploid embryos. Mitosis errors can occur at all stages of early embryo development that result in chromosomally distinct cell populations. The clinical impact of mosaicism depends on the mosaicism type, location, and number of aneuploid cells. Transfer of mosaic embryos has been proposed when no euploid embryos are available in the PGT-A cycle.

Reproduction (2020) 160 A33-A44
\end{abstract}

\section{Introduction}

Aneuploidy is the most common chromosomal abnormality observed in human embryos. Trisomic and monosomic embryos account for at least $10 \%$ of human pregnancies, and that incidence may exceed $50 \%$ for women nearing the end of their reproductive lifespan (Nagaoka et al. 2012, Soler et al. 2017). Further, aneuploidy rates are higher in oocytes and embryos from women of advanced maternal age (AMA) (Rubio et al. 2019b), probably stemming from meiotic recombination defects exacerbated by age (Herbert et al. 2015). Recent studies of humans and model organisms have shed new light on the complexity of meiotic defects, providing evidence that age-related increase in errors in human females is not attributable to a single factor but to an interplay of unique features of oogenesis and a host of endogenous and exogenous factors (Nagaoka et al. 2012). Age-related defects result in higher aneuploidy rates in offspring and increased spontaneous abortions, thereby reducing ongoing implantation rates. Aneuploidy may also be a contributing factor in other infertile populations, such as couples with recurrent miscarriages (Sugiura-Ogasawara et al. 2012) or repetitive implantation failure (Margalioth et al. 2006). In male infertility, an increase in sperm chromosomal abnormalities due to impairment of the meiotic process has been described (Silber et al. 2003, Rodrigo et al. 2011). Additionally, a higher incidence of aneuploidy has been described in miscarriages of couples undergoing intracytoplasmic sperm injection (ICSI) because of male infertility (Kim et al. 2010, Campos-Galindo et al. 2015).

\section{Preimplantation genetic testing for aneuploidy}

Aneuploidy rates are high in human embryos and they increase with advancing female age (Franasiak et al. 2014, Rubio et al. 2019a). For this reason, aneuploidy testing in embryo biopsies known as preimplantation genetic testing for aneuploidy (PGTA), was incorporated in IVF programs with the aim to improve pregnancy rates per transfer and to decrease miscarriage rates in infertile couples. However, the potential benefits of PGT-A were questioned after 
the publication of several randomized controlled trials (RCT) using fluorescence in situ hybridisation (FISH) and cleavage-stage biopsies, in which no improvement in live birth rates were observed (reviewed by Mastenbroek et al. 2011). Later on, another RCT using FISH in patients with advanced maternal age (AMA) between 41 and 44 years of age showed increased live birth rates per patient using PGT-A and increased cumulative ongoing pregnancy rates (Rubio et al. 2013). The discrepancy with the previous studies could be due to differences in the FISH technique as well as the age range, with younger women included in the previous ones. In the same publication, the authors did not find a benefit with PGT-A for repetitive implantation failure, despite live birth rates per patient were 20 points higher in the PGT-A group (Rubio et al. 2013).

One of the main limitations of FISH was the limited number of chromosomes that could be analysed in a single biopsy. Later on, new technologies emerged that allowed the analysis of the 23 chromosome pairs, such as SNP arrays (Treff et al 2010), quantitative PCR (qPCR) (Treff et al. 2012), array comparative genome hybridisation (aCGH) (Gutierrez-Mateo et al. 2011), and next-generation sequencing (NGS) (Wells et al. 2014) (Fig. 1). NGS was also linked to improvements in clinical outcomes compared to aCGH for couples undergoing single embryo transfer (SET) (Friedenthal et al. 2018).

With the introduction of NGS in the PGT-A field, new types of chromosomal abnormalities can be detected in trophectoderm (TE) biopsies, with the identification of different levels of mosaicism. However, the diagnosis of mosaicism requires several considerations. The accuracy of NGS results depends on one hand on the quality of the sequencing results, and a proper validation is required for each platform and protocol to define the level of mosaicism that can be detected with a balance between sensitivity and specificity (Goodrich et al. 2016). On the hand, there are biological differences among biopsies related to the number of cells biopsied and their integrity. Also, subjectivity among different observers can be a source of variability in the diagnosis of mosaicism. Therefore, there is a need for objective evaluation of sequencing data and the development of specific algorithms to interpret the different levels of mosaicism (Goodrich et al. 2016). In addition, there has been a number of publications comparing the clinical outcome after the transfer of euploid and mosaic embryos, suggesting lower implantation and higher miscarriage rates with the transfer of mosaic embryos, with poorer prognosis with higher mosaicism levels (Greco et al. 2015, Fragouli et al. 2017, Munné et al. 2017, 2019a,b, Spinella et al. 2018, Victor et al. 2019).

In the first studies published in the PGT-A field, the main indications were to increase implantation and pregnancy rates and to decrease miscarriage rates and the risk of aneuploid offspring. However, in more recent publications, the time to conceive, the number of transfers required, and the associated cost are considered important benefits of PGT-A compared to conventional IVF (Neal et al. 2018, Somigliana et al. 2019).

Currently, most PGT-A programs are based on TE biopsy, vitrification, and deferred transfer. Coates et al. compared the results of deferred cycles with fresh transfers and found similar implantation rate per

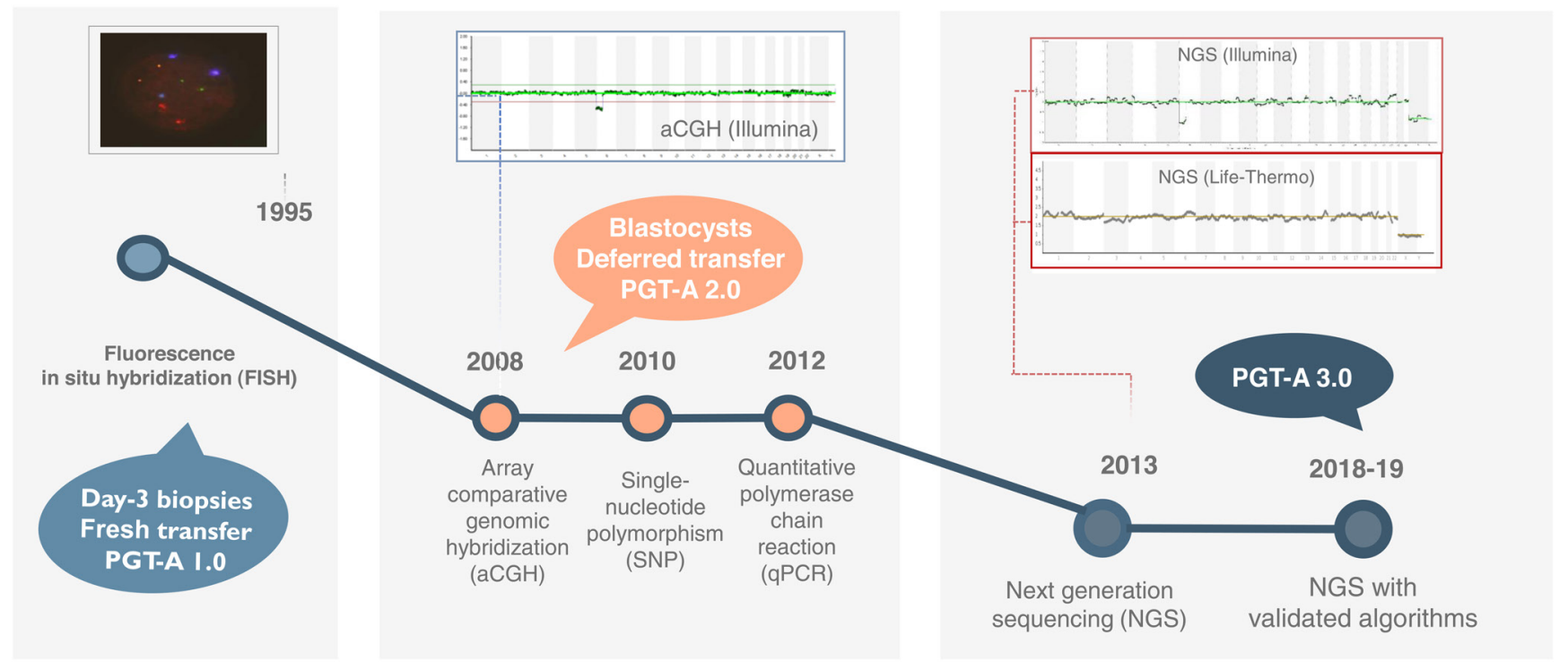

$\leq 12$ chromosomes

24 chromosomes

\section{MOSAICISM}

Figure 1 Evolution of PGT-A technology from day-blastomere biopsy using FISH technology to trophectoderm biopsy and NGS technology. 
transferred embryo in deferred cycles (75\% vs $67 \%$ ), and significantly higher ongoing pregnancy rates $(80 \%$ vs $61 \%)$ and live birth rates (77\% vs $59 \%$ ) in deferred cycles compared to fresh transfers (Coates et al. 2017).

Natsuaki and Dimler (2018) recently addressed the safety of embryo biopsy in a meta-analysis and systematic review of all reports investigating neonatal outcomes after PGT for standard IVF up to 9 years of age. They included 18 studies for childhood outcomes, which entailed anthropometric, psychomotor, cognitive, behavioural, and family functioning data. Regardless of the biopsy stage and method, PGT did not impact neonatal and postnatal outcomes, indicating the safety of approaches used to date. Further, He et al. (2019) reviewed neonatal outcomes in children born from cryopreserved blastocysts with and without TE biopsy and concluded that TE biopsy does not add additional risk.

\section{Non-invasive PGT-A (niPGT-A)}

More recently, a new perspective in the field of PGT-A has emerged - the non-invasive analysis of the cellfree DNA (cfDNA) secreted by the embryo to the culture media (Fig. 2). After initial demonstration of embryonic cfDNA in spent blastocyst media (SBM) and the possibility of identifying chromosome copy number (Shamonki et al. 2016), several studies have explored concordance between cfDNA in SBM and DNA from the human embryo obtained from polar bodies (PB) (Feichtinger et al. 2017), TE biopsies (Xu et al. 2016,

\section{Conventional preimplantation genetic} testing for aneuploidies (PGT-A)

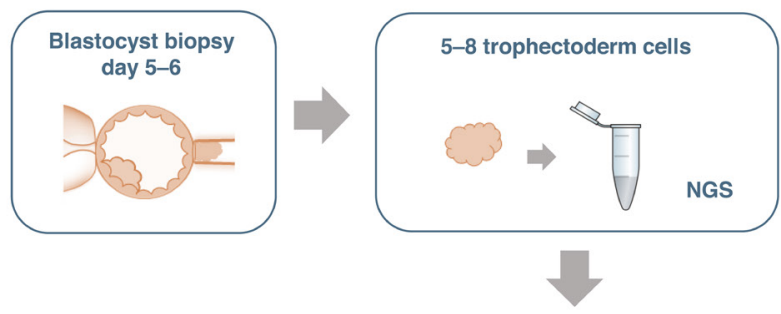

NGS trophectoderm biopsy $45,-16, X X$

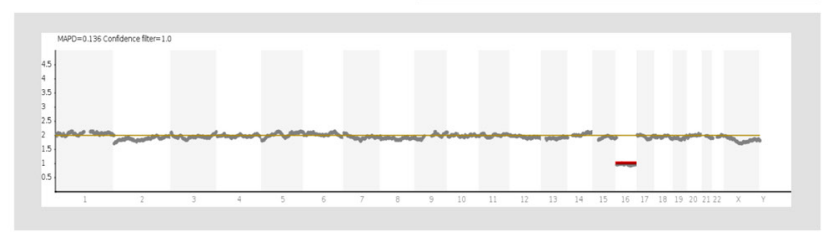

* NGS: Next Generation Sequencing
Ho et al. 2018, Vera-Rodriguez et al. 2018, Yeung et al. 2019, Rubio et al. 2019b), and whole blastocysts (Huang et al. 2019).

In these studies, informative rates for cfDNA in terms of successful amplification and interpretable NGS results ranged $80-100 \%$. Concordance rates varied from 3.4 to $85.7 \%$ for PB and TE biopsies (Shamonki et al. 2016, $\mathrm{Xu}$ et al. 2016, Ho et al. 2018, Vera-Rodriguez et al. 2018, Yeung et al. 2019) and increased up to $93.8 \%$ when compared with whole blastocysts, suggesting that niPGT-A could be more representative of embryo chromosomal status than TE biopsies (Huang et al. 2019). Since the first proof-of-concept paper (Shamonki et al. 2016), technology development and new IVF culture protocols have markedly increased concordance rates between TE and SBM. Nevertheless, in all these studies, embryos were previously manipulated in some way, with assisted hatching, biopsy, or vitrification. However, another study achieved a high concordance rate (84\%) on day 6 blastocysts without any previous manipulation (Rubio et al. 2019b).

Further, another study compared results from a combination of blastocoel fluid and SBM analysis with TE and with whole blastocysts and found higher concordance rates between media and whole-blastocyst embryos than between TE and whole blastocysts, pointing out that blastocoel fluid and SBM could be more representative of 'true' embryo chromosomal content than TE (Kuznyetsov et al. 2018). Another study indicated similar results clinically, with decreased miscarriage rates when transferred blastocysts had
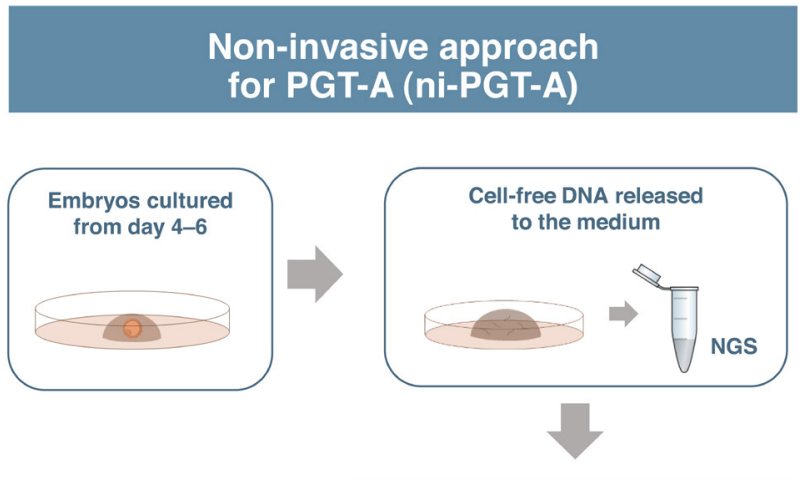

NGS in spent blastocyst media $45,-16, X X$

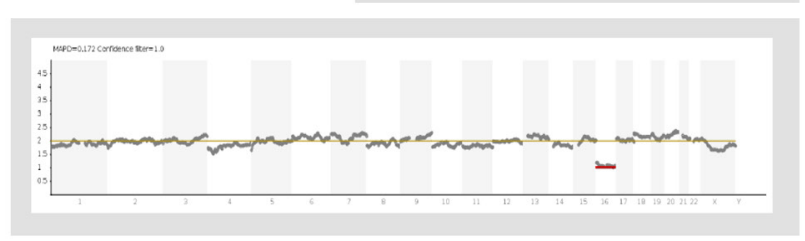

Figure 2 Schematic comparison of aneuploidy analysis in blastocyst, with trophectoderm biopsy and with the analysis of the embryonic cell-free DNA in the spent blastocyst medium. 
euploid TE and euploid SBM compared with euploid TE and aneuploid SBM (Rubio et al. 2019b).

The origin of the embryonic cfDNA is uncertain, a recent study (Rubio et al. 2020) has found similar concordance rates of the cfDNA with TE biopsy and with the inner cell mass biopsy (87.5 and 84.5\%, respectively). In another publication, it was suggested that the cfDNA could be more representative of the chromosome content of the full blastocyst than the TE biopsy, due to the high concordance rates observed with the whole blastocyst (Huang et al. 2019). However, the reply to this article argued that TE cells should be the main source for the cfDNA secreted to the medium, since TE cells are in direct contact with the medium and they are higher in number compared to the inner cell mass (Gleicher \& Barad 2019).

A non-invasive approach to assess the chromosomal status of embryos could have several important advantages compared to current invasive PGT-A with TE biopsy. Such advantages include avoiding invasiveness and potential embryo harm, as well as extending the feasibility of PGT-A in a larger number of clinics and increasing its accessibility to a wider population of patients by minimising laboratory and personnel expenses. Therefore, this approach would be accessible worldwide. However, further clinical studies and more basic research are needed to fully address remaining questions related to the origin of cfDNA, its representativeness of the full embryo chromosome content, and its potential clinical applications to improve IVF outcomes.

\section{Aneuploidy of maternal origin}

Chromosome abnormalities mostly originate in female meiosis (Hassold \& Hunt 2009). Recombination between homologous chromosomes is a critical event that occurs in the foetal ovary (Gruhn et al. 2013). The importance of altered recombination pertains to paternally as well as maternally derived trisomies, but as most aneuploidy arises during oogenesis, the female is at greater risk. Therefore, either more recombination errors are made in females or these errors are more efficiently culled in males (Hassold \& Hunt 2009). Immunofluorescence has made it possible to examine crossover-associated proteins in pachytene spermatocytes and oocytes to test these alternatives. Strikingly, almost all chromosomes in males are joined by at least one crossover, although the same does not apply to females. Indeed, $>10 \%$ of all human oocytes contain at least one 'crossover-less' bivalent. Because half of all such bivalents are expected to result in aneuploidy, the stage appears to be set for meiotic errors from the beginning of oogenesis (reviewed by Nagaoka et al. 2012).

Female age has a strong impact in the incidence of aneuploidy, and this is the most important contributing factor for the high incidence of aneuploidies in women of advanced age (Franasiak et al. 2014, Rubio et al. 2019a). Fertility declines as women age, owing to both a diminished ovarian reserve and impaired oocyte quality that leads to an increase in embryo aneuploidy in humans (Gruhn et al. 2019). In this recent study, the authors proposed that chromosomal errors originating in oocytes determine the curve of natural fertility in humans in women from 9 to 43 years. In the same study, it was described that whole-chromosome nondisjunction events are preferentially associated with increased aneuploidy in young women ( $>20$ years), whereas centromeric and more extensive cohesion loss limit fertility as women age ( $\geq 33$ years).

Different models have been proposed to explain the effect of female age on aneuploidy. One of the earliest models of the maternal-age effect in mammals was the 'production-line model' with two key assumptions: first, that oocytes entering first meiosis were the first ovulated; and second, that the first to enter meiosis have more recombination events (crossovers) than those that enter meiosis later in foetal life (Herderson et al. 1968). However, a later molecular cytogenetic study of secondtrimester human foetal ovaries directly examined the number and distribution of crossover-associated proteins in prophase-stage oocytes, showing similar recombination levels between oocytes entering meiosis early in foetal life and those entering late in foetal life. This study concluded that the production-line model is not the basis for the maternal-age effect on trisomy on humans (Rowsey et al. 2014).

Another source of chromosome segregation errors and aneuploidy in oocytes from older women is premature loss of centromeric cohesion (Herbert et al. 2015, Zielinska et al. 2015, Lagirand-Cantaloube et al. 2017). More lately, female age has been proposed to impact interactions between spindle microtubules and kinetochores as drivers of chromosome segregation in three mammalian species: mice, pig and humans. Centromeric chromatin recompacts with AMA, and kinetochores built on decompacted centromeres frequently lose their integrity and fragment into multiple lobes. The partial cohesin loss that occurs in oocytes with AMA is enough to trigger centromere decompaction and kinetochore fragmentation. Fragmented kinetochores are frequently abnormally attached to spindle microtubules, suggesting that kinetochore fragmentation could contribute to the maternal-age effect in mammalian eggs (Zielinska et al. 2019).

Due to all the previously described evidence that female age is the main contributor to embryo aneuploidy, this was the first group of patients in which PGT-A was proposed. A study of PB biopsies reported that the rate of mis-segregation for most clinically relevant aneuploidies (chromosomes 13, 16, and 18) increased from 20 to $60 \%$ in women with age range between 35 and 43 years of age (Kuliev et al. 2011). At cleavage stage, four RCTs were published for women of AMA 
using FISH for a limited number of chromosomes. Three indicated that PGT-A offered no benefit (reviewed by Mastenbroek et al. 2011). However, these studies have been criticized by several authors who argue that the methodologies had some important pitfalls, including patient inclusion criteria, embryo biopsy procedures, embryo culture conditions, and type of genetic analyses performed. The fourth study in women of 41-44 years of age showed a significant increase in live birth rates with PGT-A compared to a conventional blastocyst transfer (32.3\% vs $15.5 \%$; $P=0.0099$ ) (Rubio et al. 2013). Later, another RCT study using aCGH showed similar cumulative pregnancy rates, but confirmed higher live birth rates per transfer and decreased miscarriage rates and number of transfers needed to achieve an ongoing pregnancy with PGT-A in women 38-41 years of age (Rubio et al. 2017).

More recently, an RCT using NGS and TE biopsy showed a potential benefit of PGT-A in a subgroup of women aged 35-40 years who had two or more embryos that could be biopsied, but this was not significant when analysed by intention to treat (Munné et al. 2019b). Further, a retrospective observational study reported the results of clinical, gestational, and neonatal outcomes for women of AMA after 2 years follow-up. The study included a control group of 2538 couples undergoing 2905 egg collections, 308 couples undergoing PGT-A, and 106 couples in a drop-out group who consented to PGT-A but withdrew due to poor embryological outcomes. The authors concluded that PGT-A improves clinical outcomes, particularly by reducing pregnancy loss and chromosomally abnormal pregnancy for patients of AMA, with no major impact on cumulative live birth rate per egg retrieval (Sacchi et al. 2019).

Finally, with the introduction of NGS, PGT-A cost is becoming increasingly affordable and enables embryo chromosome analysis in IVF at lower cost. Comparison of the cost-effectiveness between two IVF treatment strategies, serial transfer of all available blastocysts without genetic testing (first fresh transfer and subsequent frozen-thawed transfer), and systematic use of genetic testing (TE biopsy, freeze-all, and frozenthawed transfers of euploid blastocysts) demonstrates the cost-effectiveness of PGT-A with increased female age and number of available blastocysts (Neal et al. 2018, Somigliana et al. 2019).

\section{Sperm contribution to embryo aneuploidies}

Sperm aneuploidy has been described as a contributing factor for embryo aneuploidy (Rodrigo et al. 2010, Daughtry \& Chavez 2016). Aneuploid and diploid sperm can be originated by meiotic errors in the synapsis, recombination, or DNA repair mechanisms (Nicklas et al. 1997, Vendrell et al. 1999, Egozcue et al. 2000a,b). With the introduction of ICSI, prenatal follow-up revealed an increased incidence of de novo sex chromosome aneuploidies and structural rearrangements that were attributed mostly to sperm quality (Van Opstal et al. 1997) Since then, sperm aneuploidy has been associated with lower pregnancy and implantation rates and to higher miscarriage rates after ICSI (Rubio et al. 2001, Petit et al. 2005, Nicopoullos et al. 2008, Sarrate et al. 2010).

FISH technology in decondensed sperm heads was employed for the analysis of sperm aneuploidies. FISH studies on sperm over the past 20 years have shown a higher incidence of sperm aneuploidies in infertile males compared to the fertile population (Bernardini et al. 1998, Aran et al. 1999, Pang et al. 1999, Ushijima et al. 2000, Ramasamy et al. 2015, Rodrigo et al. 2019). FISH analysis of sperm has been applied mainly to patients with impaired sperm parameters (low concentration, impaired motility or abnormal morphology), and to couples with a clinical history of recurrent miscarriage or repetitive implantation failure (In't Veld et al. 1997, Pang et al. 1999, Rubio et al. 2001, 2009, Martin et al. 2003, Rodrigo et al. 2004, 2019, Petit et al. 2005, Vialard et al. 2008, Sarrate et al. 2010, Ramasamy et al. 2015).

The clinical outcome of couples with a normal sperm FISH was similar with conventional IVF/ICSI or PGT-A treatments. However, in treatments with abnormal sperm FISH, PGT-A with the transfer of euploid embryos offered better clinical outcomes (Rodrigo et al. 2019). Similarly, two small studies including 29 and 56 patients supported an association between total sperm aneuploidy rate and clinical pregnancy, with lower clinical pregnancy rates in patients with higher sperm aneuploidy (Petit et al. 2005, Nicopoullos et al. 2008).

Although most embryo chromosomal abnormalities miscarry or do not implant, several studies have reported ongoing pregnancies in which the fathers have increased sperm chromosomal abnormalities associated with the chromosomal abnormalities observed in their children. Blanco et al. (1998) described a high incidence of sperm with disomy for chromosome 21 in two men $(0.75$ and $0.78 \%)$ with children with Down syndrome, with a paternal origin of the extra chromosome 21 . Similar reports in couples who miscarry or have children with aneuploidies for sex chromosomes, such as Turner syndrome or Klinefelter syndrome, have described high incidence of sperm with aneuploidies for sex chromosomes ranging $0.20-24.7 \%$ after sperm FISH analysis (Martínez-Pasarell et al. 1999, Lowe et al. 2001, Eskenazi et al. 2002, Tang et al. 2004).

Regarding sperm concentration and aneuploidy risk, the first studies were performed in testicular biopsies to assess the meiotic process. Oligozoospermic males showed a higher incidence of abnormal chromosome pairing (Vendrell et al. 1999, Egozcue et al. 2000b). Then, FISH studies in ejaculated sperm revealed an association of aneuploid and diploid sperm with oligozoospermia (Rubio et al. 2001, Martin et al. 2003, Nagvenkar et al. 
2005, Durak Aras et al. 2012, Rodrigo et al. 2019). This correlation has also been observed in testicular sperm from azoospermic males, mainly those with nonobstructive azoospermia, where up to $42 \%$ of men have an abnormal FISH results (Rodrigo et al. 2011).

However, the correlation regarding sperm motility or morphology is not as clear. Regarding sperm motility, no clear correlation of isolated sperm motility and aneuploidy was found (Samura et al. 1997, Zeyneloglu et al. 2000, Sarrate et al. 2010, Rodrigo et al. 2019). Regarding sperm morphology, controversial results have been found. Some authors did not find a relationship between sperm aneuploidy and morphology (Celik-Ozenci et al 2004, Sarrate et al. 2010, Rodrigo et al. 2019). Whereas others reported an increase in sperm aneuploidy in teratozoospermic males (Gole et al. 2001, Burrello et al. 2004). However, a general consensus seems to exist regarding severe teratozoospermia with large-headed and multiple-tailed spermatozoa or abnormal flagella for a higher risk of sperm aneuploidy, diploidy, and polyploidy, as reported in several studies with small number of patients included, ranging from a case report to 30 infertile men (Hristova et al. 2002, Tempest et al. 2004, Mateu et al. 2006, Brahem et al. 2012).

Compromised semen quality, mainly related to severe low sperm concentration, is purportedly associated with increased rates of mosaic blastocysts analysed in PGT-A cycles (Tarozzi et al. 2019). Moreover, higher rates of abnormal embryos may occur in couples with altered sperm FISH, with a high incidence of aneuploidy for sex chromosomes and mosaic embryos (Gianaroli et al. 2005, Rubio et al. 2005, Rodrigo et al.
2010, Sánchez-Castro et al. 2009). The percentage of abnormal embryos ranges $43-78 \%$ in patients with oligozoospermia and azoospermia in which abnormal sperm FISH results or impaired meiosis are reported ( Silber et al. 2003, Aran et al. 2004, Gianaroli et al. 2005, Rubio et al. 2005, Magli et al. 2009, SánchezCastro et al. 2009, Rodrigo et al. 2010, 2014, Al-Asmar et al. 2012). Further, patients with severe oligozoospermia or cryptozoospermia who are carriers of Y-chromosome microdeletions show an increase in aneuploid embryos, highlighting monosomy $\mathrm{X}$ (Mateu et al. 2010).

Therefore, an increase in the percentage of spermatozoa with sex chromosome disomies has been associated with an increase in embryo aneuploidies compatible with life (Patau, Edwards, Down, Klinefelter, and Turner syndromes; and trisomies $X X X$ and $X Y Y$ ). In contrast, an increase in diploid spermatozoa has been related to an increase in triploid embryos, which mostly miscarry before delivery (Rodrigo et al. 2010).

\section{Embryo mosaicism and mitotic errors}

Although the vast majority of aneuploidies in preimplantation embryos are due to meiotic errors, especially of maternal origin, defective mitosis may occur at all stages of early embryo development that result in chromosomally distinct cell populations - these are termed mosaic embryos, defined as embryos having cells with different chromosome constitution. The origin of mosaicism can be related to the failure of homologous chromosomes to separate due to anaphase lag and

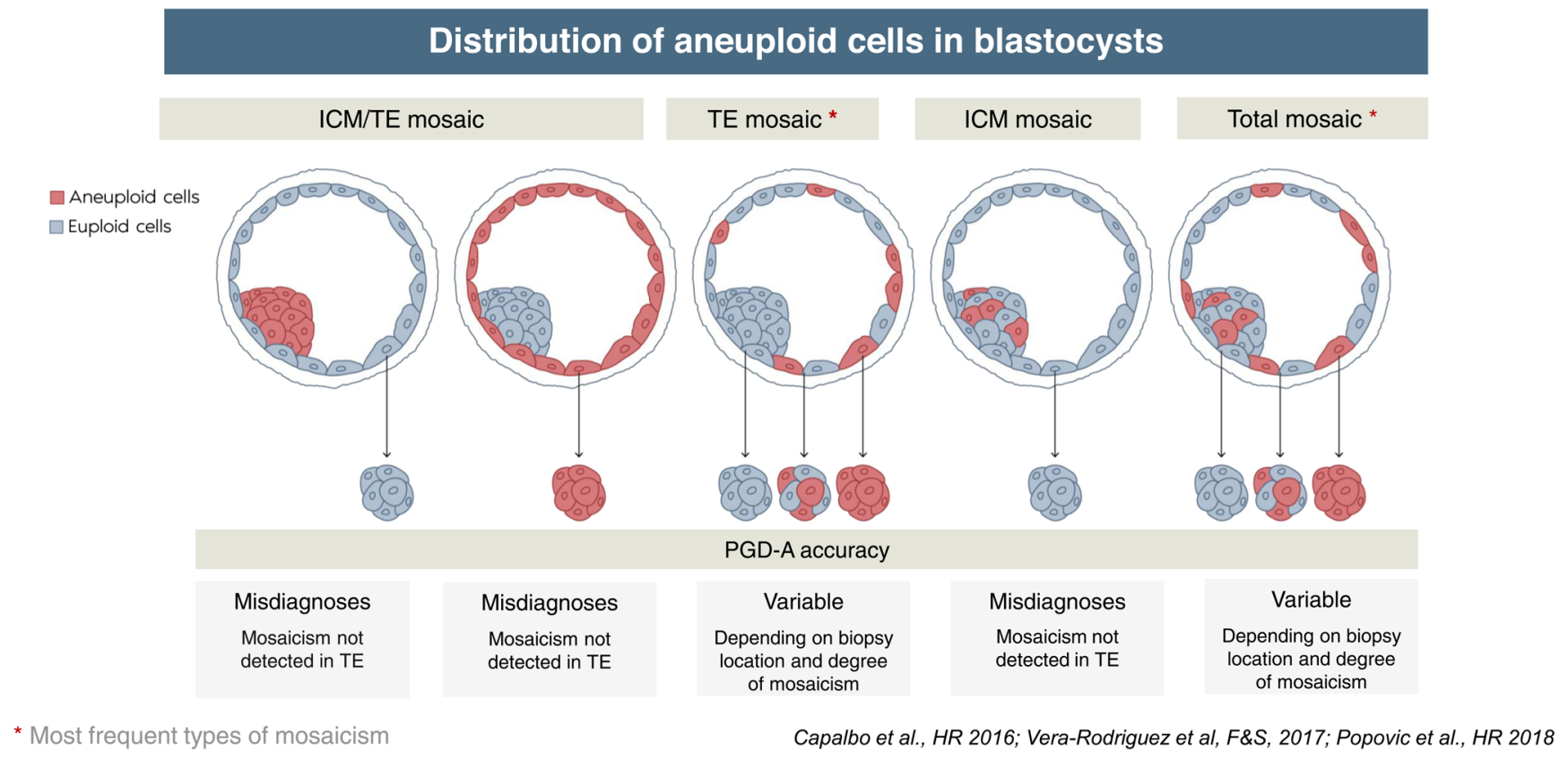

Figure 3 Mosaicism types according to the location of aneuploid cells, only in the inner cell mass (ICM), only in the trophectoderm (TE), or distributed in both blastocyst compartments. 
chromosome nondisjunction during mitosis (Conlin et al. 2010, Daughtry et al. 2016). Other suggested causes are DNA endoreduplication, cell fusion, multipolar divisions, or defective cell cycle checkpoint machinery (Mantikou et al. 2012). Blastomere fragmentation and micronuclei formation have also been associated with the presence of mosaicism in human embryos (Kort et al. 2016).

A genetic condition may increase the risk of mosaicism in some couples, identifying an association between aneuploidy of putative mitotic origin and linked genetic variants on chromosome 4 of maternal genomes. This associated region contains a candidate gene, Polo-like kinase 4 (PLK4), that plays a wellcharacterized role in centriole duplication and has the ability to alter mitotic fidelity upon minor dysregulation (McCoy et al. 2015).

Mosaicism can occur as early as the two-cell stage, although detection at the blastocyst stage is more common because more TE cells can be simultaneously analysed. At the blastocyst stage, three main types of mosaic embryos have been defined: diploid-aneuploid mosaicism, a combination of normal diploid cells and aneuploid cells; aneuploid mosaicism, with a combination of cell with different aneuploidies; and chaotic mosaicism, when the aneuploid cells have multiple aneuploid chromosomes (McCoy et al. 2017). According to the affected cell lineage a 'total mosaic' embryo is observed when aneuploid and euploid cells are found indistinctly in the inner cell mass (ICM) and TE. Alternatively, the mosaic population may be confined exclusively to one of these cell populations, thus generating 'ICM mosaicism' or 'TE mosaicism'. Finally, all cells in the ICM being aneuploid and those of the TE being euploid (or vice versa) confers 'ICM/TE mosaicism' (Fig. 3).

Accuracy in diagnosing mosaicism depends on the distribution and percentage of aneuploid cells. Therefore, biopsy information is only relevant to the biopsy itself. Nevertheless, the most common types of mosaicism detected in human blastocysts are TE mosaicism and total mosaicism, in which both TE and ICM are aneuploid. These two types of mosaicism would be detected in a TE biopsy if enough aneuploid cells are present (Capalbo et al. 2017, Vera-Rodriguez et al. 2018, Popovic et al. 2019).

Mosaicism was initially predicted more than 25 years ago from FISH analysis of two blastomeres that were assessed for PGT-A (Papadopoulos et al. 1989). Subsequently, multiple FISH studies analysing single cells of whole blastocysts have confirmed mosaicism in day 3 biopsies with non-concordance rates (when genotypes of analysed cells do not match one another) ranging 18-46\% (Li et al. 2005, Baart et al. 2006, Barbash-Hazan et al. 2009, Vanneste et al. 2009). These high non-concordance rates on day 3 suggest very high mosaicism in the cleavage-stage embryo, suggesting TE biopsy is a more reliable option for PGT-A than embryo biopsy (Harton et al. 2011).

Development of aCGH and NGS on TE biopsies has allowed new assessments of mosaicism. Several studies have used cell line mixture models to estimate the sensitivity and specificity of these methods for detecting mosaicism, estimating $40-50 \%$ levels of detection for aneuploid cells with the use of aCGH and $20 \%$ with the use of NGS (Mamas et al. 2012, Goodrich et al. 2016). Analysis of two to three biopsies in the same embryo shows concordance rates as high as $95-100 \%$. In addition, these studies also analysed ICM of the same embryos to estimate discordance frequencies between cell lineages. TE and ICM show discordant mosaicism rates of 3-4\% (Capalbo et al. 2013, Ruttanajit et al. 2016). Mosaicism detection in TE biopsies is challenging, and proper validation to define mosaicism thresholds is required for each platform to avoid overdiagnosis of mosaicism due to technical artefacts.

Mosaic embryos have been proposed for transfer if no euploid embryo are present in the PGT-A cycle (Greco et al. 2015, Fragouli et al. 2017, Victor et al. 2019). Clinical outcome has been related to the level of mosaicism (Spinella et al. 2018), chromosomes implicated (Grati et al. 2018), and number of affected chromosomes (Maxwell et al. 2016). One key aspect when reporting mosaicism in TE biopsies is to offer proper pre-cycle and post-cycle genetic counselling, informing of the limited information of risks of transferring mosaic embryos, including miscarriage, offspring with aneuploidies, intrauterine growth retardation, or uniparental disomy (Grati et al. 2018). Patients who do not have euploid embryos can opt for transfer of a mosaic embryo as an alternative if they opt for additional treatment cycles, which increases the chance of achieving an ongoing pregnancy than with mosaic transfer. However, future studies are needed to compare cost-effectiveness for both options (Besser et al. 2019).

\section{Conclusions and future perspectives}

We can conclude that PGT-A with NGS coupled with SET and deferred blastocyst transfer is the most extended approach. The published studies have shown similar cumulative pregnancy rates, but increased ongoing pregnancy rates per transfer, allowing to decrease the number of transfers required to achieve a healthy pregnancy, and therefore the time to pregnancy and the final cost is some cases. Several studies have confirmed the safety of embryo biopsy and that PGT does not impact neonatal and postnatal outcomes, indicating the safety of approaches used up to date.

A non-invasive approach to study the chromosomal status of embryos could have several important advantages over current invasive PGT-A with TE biopsy. A 
major advantage is avoiding invasiveness with potential embryo harm, as well as extending the feasibility of PGT-A in a larger number of clinics and accessibility to a wider population of patients by minimising laboratory and personnel expenses. Therefore, this approach would be accessible worldwide. However, clinical studies and more basic research are needed to fully address remaining questions related to the origin of cfDNA, its representativeness of the full embryo chromosome content, and its potential clinical applications to improve IVF outcomes.

\section{Declaration of interest}

The authors declare that there is no conflict of interest that could be perceived as prejudicing the impartiality of this review.

\section{Funding}

This research did not receive any specific grant from any funding agency in the public, commercial or not-for-profit sector.

\section{Author contribution statement}

C R conceived the outline of the review and wrote part of the paper. L R wrote part of the paper. C S reviewed the paper.

\section{References}

Al-Asmar N, Peinado V, Vera M, Remohí J, Pellicer A, Simón C, Hassold T \& Rubio C 2012 Chromosomal abnormalities in embryos from couples with a previous aneuploid miscarriage. Fertility and Sterility 98 145-150. (https://doi.org/10.1016/j.fertnstert.2012.03.035)

Aran B, Blanco J, Vidal F, Vendrell JM, Egozcue S, Barri PN, Egozcue J \& Veiga A 1999 Screening for abnormalities of chromosomes X, Y, and 18 and for diploidy in spermatozoa from infertile men participating in an in vitro fertilization-intracytoplasmic sperm injection program. Fertility and Sterility 72 696-701. (https://doi.org/10.1016/s00150282(99)00307-6)

Aran B, Veiga A, Vidal F, Parriego M, Vendrell JM, Santaló J, Egozcue J \& Barri PN 2004 Preimplantation genetic diagnosis in patients with male meiotic abnormalities. Reproductive Biomedicine Online 8 470-476. (https://doi.org/10.1016/s1472-6483(10)60932-7)

Baart EB, Martini E, van den Berg I, Macklon NS, Galjaard RJ, Fauser BC \& Van Opstal D 2006 Preimplantation genetic screening reveals a high incidence of aneuploidy and mosaicism in embryos from young women undergoing IVF. Human Reproduction 21 223-233. (https://doi. org/10.1093/humrep/dei291)

Barbash-Hazan S, Frumkin T, Malcov M, Yaron Y, Cohen T, Azem F, Amit A \& Ben-Yosef D 2009 Preimplantation aneuploid embryos undergo selfcorrection in correlation with their developmental potential. Fertility and Sterility 92 890-896. (https://doi.org/10.1016/j.fertnstert.2008.07.1761)

Bernardini L, Borini A, Preti S, Conte N, Flamigni C, Capitanio GL \& Venturini PL 1998 Study of aneuploidy in normal and abnormal germ cells from semen of fertile and infertile men. Human Reproduction 13 3406-3413. (https://doi.org/10.1093/humrep/13.12.3406)

Besser AG, McCulloh DH \& Grifo JA 2019 What are patients doing with their mosaic embryos? Decision making after genetic counseling. Fertility and Sterility 111 132.e1-137.e1. (https://doi.org/10.1016/j. fertnstert.2018.10.001)
Blanco J, Gabau E, Gómez D, Baena N, Guitart M, Egozcue J \& Vidal F 1998 Chromosome 21 disomy in the spermatozoa of the fathers of children with trisomy 21. American Journal of Human Genetics 63 1067-1072. (https://doi.org/10.1086/302058)

Brahem S, Mehdi M, Elghezal H \& Saad A 2012 Study of aneuploidy rate and sperm DNA fragmentation in large-headed, multiple-tailed spermatozoa. Andrologia 44 130-135. (https://doi.org/10.1111/j.14390272.2010.01115.x)

Burrello N, Arcidiacono G, Vicari E, Asero P, Di Benedetto D, De Palma A, Romeo R, D'Agata R \& Calogero AE 2004 Morphologically normal spermatozoa of patients with secretory oligo-astheno-teratozoospermia have an increased aneuploidy rate. Human Reproduction 19 2298-2302. (https://doi.org/10.1093/humrep/deh438)

Campos-Galindo I, García-Herrero S, Martínez-Conejero JA, Ferro J, Simón C \& Rubio C 2015 Molecular analysis of products of conception obtained by hysteroembryoscopy from infertile couples. Journal of Assisted Reproduction and Genetics 32 839-848. (https://doi. org/10.1007/s10815-015-0460-z)

Capalbo A, Wright G, Elliott T, Ubaldi FM, Rienzi L \& Nagy ZP 2013 FISH reanalysis of inner cell mass and trophectoderm samples of previously array-CGH screened blastocysts shows high accuracy of diagnosis and no major diagnostic impact of mosaicism at the blastocyst stage. Human Reproduction 28 2298-2307. (https://doi.org/10.1093/humrep/det245)

Capalbo A, Ubaldi FM, Rienzi L, Scott R \& Treff N 2017 Detecting mosaicism in trophectoderm biopsies: current challenges and future possibilities. Human Reproduction 32 492-498. (https://doi. org/10.1093/humrep/dew250)

Celik-Ozenci C, Jakab A, Kovacs T, Catalanotti J, Demir R, Bray-Ward P, Ward D \& Huszar G 2004 Sperm selection for ICSI: shape properties do not predict the absence or presence of numerical chromosomal aberrations. Human Reproduction 19 2052-2059. (https://doi. org/10.1093/humrep/deh361)

Coates A, Kung A, Mounts E, Hesla J, Bankowski B, Barbieri E, Ata B, Cohen J \& Munné S 2017 Optimal euploid embryo transfer strategy, fresh versus frozen, after preimplantation genetic screening with next generation sequencing: a randomized controlled trial. Fertility and Sterility 107723. e3-730.e3. (https://doi.org/10.1016/j.fertnstert.2016.12.022)

Conlin LK, Thiel BD, Bonnemann CG, Medne L, Ernst LM, Zackai EH, Deardorff MA, Krantz ID, Hakonarson H \& Spinner NB 2010 Mechanisms of mosaicism, chimerism and uniparental disomy identified by single nucleotide polymorphism array analysis. Human Molecular Genetics 19 1263-1275. (https://doi.org/10.1093/hmg/ddq003)

Daughtry BL \& Chavez SL 2016 Chromosomal instability in mammalian preimplantation embryos: potential causes, detection methods, and clinical consequences. Cell and Tissue Research 363 201-225. (https:// doi.org/10.1007/s00441-015-2305-6)

Durak Aras B, Aras I, Can C, Toprak C, Dikoglu E, Bademci G, Ozdemir M, Cilingir O \& Artan S 2012 Exploring the relationship between the severity of oligozoospermia and the frequencies of sperm chromosome aneuploidies. Andrologia 44 416-422. (https://doi.org/10.1111/j.14390272.2012.01298.x)

Egozcue S, Blanco J, Vendrell JM, García F, Veiga A, Aran B, Barri PN, Vidal F \& Egozcue J 2000a Human male infertility: chromosome anomalies, meiotic disorders, abnormal spermatozoa and recurrent abortion. Human Reproduction Update 6 93-105. (https://doi. org/10.1093/humupd/6.1.93)

Egozcue S, Vendrell JM, Garcia F, Veiga A, Aran B, Barri PN \& Egozcue J $2000 \mathrm{~b}$ Increased incidence of meiotic anomalies in oligoasthenozoospermic males preselected for intracytoplasmic sperm injection. Journal of Assisted Reproduction and Genetics 17 307-309. (https://doi.org/10.1023/A:1009444709504)

Eskenazi B, Wyrobek AJ, Kidd SA, Lowe X, Moore D 2nd, Weisiger K \& Aylstock M 2002 Sperm aneuploidy in fathers of children with paternally and maternally inherited Klinefelter syndrome. Human Reproduction 17 576-583. (https://doi.org/10.1093/humrep/17.3.576)

Feichtinger M, Vaccari E, Carli L, Wallner E, Mädel U, Figl K, Palini S \& Feichtinger W 2017 Non-invasive preimplantation genetic screening using array comparative genomic hybridization on spent culture media: a proof-of-concept pilot study. Reproductive Biomedicine Online $\mathbf{3 4}$ 583-589. (https://doi.org/10.1016/j.rbmo.2017.03.015)

Fragouli E, Alfarawati S, Spath K, Babariya D, Tarozzi N, Borini A \& Wells D 2017 Analysis of implantation and ongoing pregnancy rates 
following the transfer of mosaic diploid-aneuploid blastocysts. Human Genetics 136 805-819. (https://doi.org/10.1007/s00439-017-1797-4)

Franasiak JM, Forman EJ, Hong KH, Werner MD, Upham KM, Treff NR \& Scott Jr RT 2014 The nature of aneuploidy with increasing age of the female partner: a review of 15,169 consecutive trophectoderm biopsies evaluated with comprehensive chromosomal screening. Fertility and Sterility 101 656.e1-663.e1. (https://doi.org/10.1016/j. fertnstert.2013.11.004)

Friedenthal J, Maxwell SM, Munné S, Kramer Y, McCulloh DH, McCaffrey C \& Grifo JA 2018 Next generation sequencing for preimplantation genetic screening improves pregnancy outcomes compared with array comparative genomic hybridization in single thawed euploid embryo transfer cycles. Fertility and Sterility 109 627-632. (https://doi. org/10.1016/j.fertnstert.2017.12.017)

Gianaroli L, Magli MC \& Ferrareti AP 2005 Sperm and blastomere aneuploidy detection in reproductive genetics and medicine. Journal of Histochemistry and Cytochemistry 53 261-267. (https://doi. org/10.1369/jhc.4B6434.2005)

Gleicher N \& Barad DH 2019 Not even noninvasive cell-free DNA can rescue preimplantation genetic testing. PNAS 116 21976-21977. (https://doi.org/10.1073/pnas.1911710116)

Gole LA, Wong PF, Ng PL, Wang XQ, Ng SC \& Bongso A 2001 Does sperm morphology play a significant role in increased sex chromosomal disomy? A comparison between patients with teratozoospermia and OAT by FISH. Journal of Andrology 22 759-763.

Goodrich D, Tao X, Bohrer C, Lonczak A, Xing T, Zimmerman R, Zhan Y, Scott RT Jr \& Treff NR 2016 A randomized and blinded comparison of qPCR and NGS-based detection of aneuploidy in a cell line mixture model of blastocyst biopsy mosaicism. Journal of Assisted Reproduction and Genetics 33 1473-1480. (https://doi.org/10.1007/s10815-0160784-3)

Grati FR, Gallazzi G, Branca L, Maggi F, Simoni G \& Yaron Y 2018 An evidence-based scoring system for prioritizing mosaic aneuploid embryos following preimplantation genetic screening. Reproductive Biomedicine Online $36 \quad 442-449$. (https://doi.org/10.1016/j. rbmo.2018.01.005)

Greco E, Minasi MG \& Fiorentino F 2015 Healthy babies after intrauterine transfer of mosaic aneuploid blastocysts. New England Journal of Medicine 373 2089-2090. (https://doi.org/10.1056/NEJMc1500421)

Gruhn JR, Rubio C, Broman KW, Hunt PA \& Hassold T 2013 Cytological studies of human meiosis: sex-specific differences in recombination originate at, or prior to, establishment of double-strand breaks. PLOS ONE 8 e85075. (https://doi.org/10.1371/journal.pone. 0085075)

Gutierrez-Mateo C, Colls P, Sanchez-Garcia J, Escudero T, Prates R, Ketterson K, Wells D \& Munne S 2011 Validation of microarray comparative genomic hybridization for comprehensive chromosome analysis of embryos. Fertility and Sterility 95 953-958. (https://doi. org/10.1016/j.fertnstert.2010.09.010)

Harton GL, Magli MC, Lundin K, Montag M, Lemmen J \& Harper JC 2011 Eshre PGD Consortium/Embryology Special Interest Group - best practice guidelines for polar body and embryo biopsy for preimplantation genetic diagnosis/screening (PGD/PGS). Human Reproduction 26 41-46. (https://doi.org/10.1093/humrep/deq265)

Hassold T \& Hunt P 2009 Maternal age and chromosomally abnormal pregnancies: what we know and what we wish we knew. Current Opinion in Pediatrics 21 703-708. (https://doi.org/10.1097/ MOP.0b013e328332c6ab)

He H, Jing S, Lu CF, Tan YQ, Luo KL, Zhang SP, Gong F, Lu GX \& Lin G 2019 Neonatal outcomes of live births after blastocyst biopsy in preimplantation genetic testing cycles: a follow-up of 1,721 children. Fertility and Sterility 112 82-88. (https://doi.org/10.1016/j.fertnstert. 2019.03.006)

Herbert M, Kalleas D, Cooney D, Lamb M \& Lister L 2015 Meiosis and maternal aging: insights from aneuploid oocytes and trisomy births. Cold Spring Harbor Perspectives in Biology 7 a017970. (https://doi. org/10.1101/cshperspect.a017970)

Ho JR, Arrach N, Rhodes-Long K, Ahmady A, Ingles S, Chung K, Bendikson KA, Paulson RJ \& McGinnis LK 2018 Pushing the limits of detection: investigation of cell-free DNA for aneuploidy screening in embryos. Fertility and Sterility 110 467.e2-475.e2. (https://doi. org/10.1016/j.fertnstert.2018.03.036)
Hristova R, Ko E, Greene C, Rademaker A, Chernos J \& Martin R 2002 Chromosome abnormalities in sperm from infertile men with asthenoteratozoospermia. Biology of Reproduction 66 1781-1783. (https://doi.org/10.1095/biolreprod66.6.1781)

Huang L, Bogale B, Tang Y, Lu S, Xie XS \& Racowsky C 2019 Noninvasive preimplantation genetic testing for aneuploidy in spent medium may be more reliable than trophectoderm biopsy. PNAS 116 14105-14112. (https://doi.org/10.1073/pnas.1907472116)

In't Veld PA, Broekmans FJ, de France HF, Pearson PL, Pieters MH \& van Kooij RJ 1997 Intracytoplasmic sperm injection (ICSI) and chromosomally abnormal spermatozoa. Human Reproduction 12 752-754. (https://doi. org/10.1093/humrep/12.4.752)

Kim JW, Lee WS, Yoon TK, Seok HH, Cho JH, Kim YS, Lyu SW \& Shim SH 2010 Chromosomal abnormalities in spontaneous abortion after assisted reproductive treatment. BMC Medical Genetetics 3 153. (https://doi. org/10.1186/1471-2350-11-153)

Kort DH, Chia G, Treff NR, Tanaka AJ, Xing T, Vensand LB, Micucci S, Prosser R, Lobo RA, Sauer MV et al. 2016 Human embryos commonly form abnormal nuclei during development: a mechanism of DNA damage, embryonic aneuploidy, and developmental arrest. Human Reproduction 31 312-323. (https://doi.org/10.1093/humrep (dev281)

Kuliev A, Zlatopolsky Z, Kirillova I, Spivakova J \& Cieslak Janzen J 2011 Meiosis errors in over 20,000 oocytes studied in the practice of preimplantation aneuploidy testing. Reproductive Biomedicine Online 22 2-8. (https://doi.org/10.1016/j.rbmo.2010.08.014)

Kuznyetsov V, Madjunkova S, Antes R, Abramov R, Motamedi G, Ibarrientos Z \& Librach C 2018 Evaluation of a novel non-invasive preimplantation genetic screening approach. PLOS ONE 13 e0197262. (https://doi.org/10.1371/journal.pone.0197262)

Lagirand-Cantaloube J, Ciabrini C, Charrasse S, Ferrieres A, Castro A, Anahory T \& Lorca T 2017 Loss of centromere cohesion in aneuploid human oocytes correlates with decreased kinetochore localization of the sac proteins Bub1 and Bubr1. Scientific Reports 7 44001. (https://doi. org/10.1038/srep44001)

Li M, DeUgarte CM, Surrey M, Danzer H, DeCherney A \& Hill DL 2005 Fluorescence in situ hybridization reanalysis of day-6 human blastocysts diagnosed with aneuploidy on day 3. Fertility and Sterility $\mathbf{8 4}$ 1395-1400. (https://doi.org/10.1016/j.fertnstert.2005.04.068)

Lowe X, Eskenazi B, Nelson DO, Kidd S, Alme A \& Wyrobek AJ 2001 Frequency of $X Y$ sperm increases with age in fathers of boys with Klinefelter syndrome. American Journal of Human Genetics 69 1046-1054. (https://doi.org/10.1086/323763)

Magli MC, Gianaroli L, Ferraretti AP, Gordts S, Fredericks V \& Crippa A 2009 Paternal contribution to aneuploidy in preimplantation embryos. Reproductive Biomedicine Online 18 536-542. (https://doi.org/10.1016/ s1472-6483(10)60131-9)

Mamas T, Gordon A, Brown A, Harper J \& Sengupta S 2012 Detection of aneuploidy by array comparative genomic hybridization using cell lines to mimic a mosaic trophectoderm biopsy. Fertility and Sterility $\mathbf{9 7}$ 943-947. (https://doi.org/10.1016/j.fertnstert.2011.12.048)

Mantikou E, Wong KM, Repping S \& Mastenbroek S 2012 Molecular origin of mitotic aneuploidies in preimplantation embryos. Biochimica et Biophysica Acta 1822 1921-1930. (https://doi.org/10.1016/j. bbadis.2012.06.013)

Margalioth EJ, Ben-Chetrit A, Gal M \& Eldar-Geva T 2006 Investigation and treatment of repeated implantation failure following IVF-ET. Human Reproduction 21 3036-3043. (https://doi.org/10.1093/humrep/ del305)

Martin RH, Rademaker AW, Greene C, Ko E, Hoang T, Barclay L \& Chernos J 2003 A comparison of the frequency of sperm chromosome abnormalities in men with mild, moderate and severe oligozoospermia. Biology of Reproduction 69 535-539. (https://doi.org/10.1095/ biolreprod.102.015149)

Martínez-Pasarell O, Nogués C, Bosch M, Egozcue J \& Templado C 1999 Analysis of sex chromosome aneuploidy in sperm from fathers of Turner syndrome patients. Human Genetics 104 345-349. (https://doi. org/10.1007/s004390050964)

Mastenbroek S, Twisk M, van der Veen F \& Repping S 2011 Preimplantation genetic screening: a systematic review and meta-analysis of RCTs. Human Reproduction Update 17 454-466. (https://doi.org/10.1093/ humupd/dmr003) 
Mateu E, Rodrigo L, Prados N, Gil-Salom M, Remohí J, Pellicer A \& Rubio C 2006 High incidence of chromosomal abnormalities in largeheaded and multiple-tailed spermatozoa. Journal of Andrology 27 6-10. (https://doi.org/10.2164/jandrol.05033)

Mateu E, Rodrigo L, Martínez MC, Peinado V, Milán M, GilSalom M, Martínez-Jabaloyas JM, Remohí J, Pellicer A \& Rubio C 2010 Aneuploidies in embryos and spermatozoa from patients with $\mathrm{Y}$ chromosome microdeletions. Fertility and Sterility 94 2874-2877. (https://doi.org/10.1016/j.fertnstert.2010. 06.046)

Maxwell SM, Colls P, Hodes-Wertz B, McCulloh DH, McCaffrey C, Wells D, Munné S \& Grifo JA 2016 Why do euploid embryos miscarry? A case-control study comparing the rate of aneuploidy within presumed euploid embryos that resulted in miscarriage or live birth using next-generation sequencing. Fertility and Sterility 106 1414.e5-1419.e5. (https://doi.org/10.1016/j.fertnstert.2016. 08.017)

McCoy RC 2017 Mosaicism in preimplantation human embryos: when chromosomal abnormalities are the norm. Trends in Genetics 33 448-463. (https://doi.org/10.1016/j.tig.2017.04.001)

McCoy RC, Demko ZP, Ryan A, Banjevic M, Hill M, Sigurjonsson S, Rabinowitz M \& Petrov DA 2015 Evidence of selection against complex mitotic-origin aneuploidy during preimplantation development. PLoS Genetics 11 e1005601. (https://doi.org/10.1371/journal.pgen. 1005601)

Munné S, Blazek J, Large M, Martinez-Ortiz PA, Nisson H, Liu E, Tarozzi N, Borini A, Becker A, Zhang J et al. 2017 Detailed investigation into the cytogenetic constitution and pregnancy outcome of replacing mosaic blastocysts detected with the use of high-resolution nextgeneration sequencing. Fertility and Sterility 108 62.e8-71.e8. (https:// doi.org/10.1016/j.fertnstert.2017.05.002)

Munné S, Kaplan B, Frattarelli JL, Child T, Nakhuda G, Shamma FN, Silverberg K, Kalista T, Handyside AH, Katz-Jaffe M et al. 2019a Preimplantation genetic testing for aneuploidy versus morphology as selection criteria for single frozen-thawed embryo transfer in goodprognosis patients: a multicenter randomized clinical trial. Fertility and Sterility 112 1071.e7-1079.e7. (https://doi.org/10.1016/j. fertnstert.2019.07.1346)

Munné S, Spinella F, Grifo J, Zhang J, Beltran MP, Fragouli E \& Fiorentino F $2019 b$ Clinical outcomes after the transfer of blastocysts characterized as mosaic by high resolution next generation sequencing - further insights. European Journal of Medical Genetics 21103741.

Nagaoka SI, Hassold TJ \& Hunt PA 2012 Human aneuploidy: mechanisms and new insights into an age-old problem. Nature Reviews: Genetics 13 493-504. (https://doi.org/10.1038/nrg3245)

Nagvenkar P, Zaveri K \& Hinduja I 2005 Comparison of the sperm aneuploidy rate in severe oligozoospermic and oligozoospermic men and its relation to intracytoplasmic sperm injection outcome. Fertility and Sterility 84 925-931. (https://doi.org/10.1016/j.fertnstert. 2005.04.048)

Natsuaki MN \& Dimler LM 2018 Pregnancy and child developmental outcomes after preimplantation genetic screening: a meta-analytic and systematic review. World Journal of Pediatrics 14 555-569. (https://doi. org/10.1007/s12519-018-0172-4)

Neal SA, Morin SJ, Franasiak JM, Goodman LR, Juneau CR, Forman EJ, Werner MD \& Scott RT Jr 2018 Preimplantation genetic testing for aneuploidy is cost-effective, shortens treatment time, and reduces the risk of failed embryo transfer and clinical miscarriage. Fertility and Sterility 110 896-904. (https://doi.org/10.1016/j.fertnstert. 2018.06.021)

Nicklas RB 1997 How cells get the right chromosomes. Science $\mathbf{2 7 5}$ 632-637. (https://doi.org/10.1126/science.275.5300.632)

Nicopoullos JD, Gilling-Smith C, Almeida PA, Homa S, Nice L, Tempest H \& Ramsay JW 2008 The role of sperm aneuploidy as a predictor of the success of intracytoplasmic sperm injection? Human Reproduction 23 240-250. (https://doi.org/10.1093/humrep/dem395)

Pang MG, Hoegerman SF, Cuticchia AJ, Moon SY, Doncel GF, Acosta AA \& Kearns WG 1999 Detection of aneuploidy for chromosomes 4,6,7,8 ,9,10,11,12,13,17,18,21, $X$ and $Y$ by fluorescence in-situ hybridization in spermatozoa from nine patients with oligoasthenozoospermia undergoing intracytoplasmic sperm injection. Human Reproduction $\mathbf{1 4}$ $1266-1273$.
Papadopoulos G, Templeton AA, Fisk N \& Randall J 1989 The frequency of chromosome anomalies in human preimplantation embryos after in-vitro fertilization. Human Reproduction 4 91-98. (https://doi.org/10.1093/ oxfordjournals.humrep.a136853)

Petit FM, Frydman N, Benkhalifa M, Le Du A, Aboura A, Fanchin R, Frydman R \& Tachdjian G 2005 Could sperm aneuploidy rate determination be used as a predictive test before intracytoplasmic sperm injection? Journal of Andrology 26 235-241. (https://doi. org/10.1002/j.1939-4640.2005.tb01090.x)

Popovic M, Dhaenens L, Taelman J, Dheedene A, Bialecka M, De Sutter P, Chuva de Sousa Lopes SM, Menten B \& Heindryckx B 2019 Extended in vitro culture of human embryos demonstrates the complex nature of diagnosing chromosomal mosaicism from a single trophectoderm biopsy. Human Reproduction 34 758-769. (https://doi.org/10.1093/ humrep/dez012)

Ramasamy R, Scovell JM, Kovac JR, Cook PJ, Lamb DJ \& Lipshultz LI 2015 Fluorescence in situ hybridization detects increased sperm aneuploidy in men with recurrent pregnancy loss. Fertility and Sterility 103906. e1-909.e1. (https://doi.org/10.1016/j.fertnstert.2015.01.029)

Rodrigo L, Rubio C, Mateu E, Simón C, Remohí J, Pellicer A \& GilSalom M 2004 Analysis of chromosomal abnormalities in testicular and epididymal spermatozoa from azoospermic ICSI patients, by fluorescence in-situ hybridisation (FISH). Human Reproduction 19 118-123. (https://doi.org/10.1093/humrep/deh012)

Rodrigo L, Peinado V, Mateu E, Remohí J, Pellicer A, Simón C, Gil-Salom M \& Rubio C 2010 Impact of different patterns of sperm chromosomal abnormalities on the chromosomal constitution of preimplantation embryos. Fertility and Sterility 94 1380-1386. (https://doi.org/10.1016/j. fertnstert.2009.05.061)

Rodrigo L, Rubio C, Peinado V, Villamón R, Al-Asmar N, Remohí J, Pellicer A, Simón C \& Gil-Salom M 2011 Testicular sperm from patients with obstructive and nonobstructive azoospermia: aneuploidy risk and reproductive prognosis using testicular sperm from fertile donors as control samples. Fertility and Sterility 95 1005-1012. (https://doi. org/10.1016/j.fertnstert.2010.10.022)

Rodrigo L, Mateu E, Mercader A, Cobo AC, Peinado V, Milán M, AlAsmar N, Campos-Galindo I, García-Herrero S, Mir P et al. 2014 New tools for embryo selection: comprehensive chromosome screening by array comparative genomic hybridization. BioMed Research International 2014 517125. (https://doi.org/10.1155/2014/517125)

Rodrigo L, Meseguer M, Mateu E, Mercader A, Peinado V, Bori L, CamposGalindo I, Milán M, García-Herrero S, Simón C et al. 2019 Sperm chromosomal abnormalities and their contribution to human embryo aneuploidy. Biology of Reproduction 101 1091-1101. (https://doi. org/10.1093/biolre/ioz125)

Rowsey R, Gruhn J, Broman KW, Hunt PA \& Hassold T 2014 Examining variation in recombination levels in the human female: a test of the production-line hypothesis. American Journal of Human Genetics 95 108-112. (https://doi.org/10.1016/j.ajhg.2014.06.008)

Rubio C, Gil-Salom M, Simón C, Vidal F, Rodrigo L, Mínguez Y, Remohí J \& Pellicer A 2001 Incidence of sperm chromosomal abnormalities in a risk population: relationship with sperm quality and ICSI outcome. Human Reproduction 16 2084-2092. (https://doi.org/10.1093/ humrep/16.10.2084)

Rubio C, Rodrigo L, Pérez-Cano I, Mercader A, Mateu E, Buendía P, Remohí J, Simón C \& Pellicer A 2005 FISH screening of aneuploidies in preimplantation embryos to improve IVF outcome. Reproductive Biomedicine Online 11 497-506. (https://doi.org/10.1016/s14726483(10)61146-7)

Rubio C, Buendía P, Rodrigo L, Mercader A, Mateu E, Peinado V, Delgado A, Milán M, Mir P, Simón C et al. 2009 Prognostic factors for preimplantation genetic screening in repeated pregnancy loss. Reproductive Biomedicine Online 18 687-693. (https://doi.org/10.1016/s1472-6483(10)60015-6)

Rubio C, Bellver J, Rodrigo L, Bosch E, Mercader A, Vidal C, De los Santos MJ, Giles J, Labarta E, Domingo J et al. 2013 Preimplantation genetic screening using fluorescence in situ hybridization in patients with repetitive implantation failure and advanced maternal age: two randomized trials. Fertility and Sterility 99 1400-1407. (https://doi. org/10.1016/j.fertnstert.2012.11.041)

Rubio C, Bellver J, Rodrigo L, Castillón G, Guillén A, Vidal C, Giles J, Ferrando M, Cabanillas S, Remohí J et al. 2017 In vitro fertilization with preimplantation genetic diagnosis for aneuploidies in advanced 
maternal age: a randomized, controlled study. Fertility and Sterility $\mathbf{1 0 7}$ 1122-1129. (https://doi.org/10.1016/j.fertnstert.2017.03.011)

Rubio C, Rienzi L, Navarro-Sánchez L, Cimadomo D, García-Pascual CM, Soscia D, Valbuena D, Capalbo A, Ubaldi F et al. 2019a Origin of false positives and false negatives in non-invasive preimplantation genetic testing for aneuploidies. Fertility and Sterility 112 510-519.

Rubio C, Rodrigo L, Garcia-Pascual C, Peinado V, Campos-Galindo I, Garcia-Herrero S \& Simón C 2019b Clinical application of embryo aneuploidy testing by NGS. Biology of Reproduction 101 1083-1090. (https://doi.org/10.1093/biolre/ioz019)

Rubio C, Navarro-Sánchez L, García-Pascual CM, Ocali O, Cimadomo D, Venier W, Barroso G, Kopcow L, Bahçeci M, Kulmann MIR et al. 2020 Multicenter prospective study of concordance between embryo cellfree DNA and trophectoderm biopsies from 1,301 human blastocysts. American Journal of Obstetrics and Gynecology In press. (https://doi. org/10.1016/j.ajog.2020.04.035)

Ruttanajit T, Chanchamroen S, Cram DS, Sawakwongpra K, Suksalak W, Leng X, Fan J, Wang L, Yao Y \& Quangkananurug W 2016 Detection and quantitation of chromosomal mosaicism in human blastocysts using copy number variation sequencing. Prenatal Diagnosis 36 154-162. (https://doi.org/10.1002/ pd.4759)

Sacchi L, Albani E, Cesana A, Smeraldi A, Parini V, Fabiani M, Poli M, Capalbo A \& Levi-Setti PE 2019 Preimplantation genetic testing for aneuploidy improves clinical, gestational, and neonatal outcomes in advanced maternal age patients without compromising cumulative livebirth rate. Journal of Assisted Reproduction and Genetics 36 2493-2504. (https://doi.org/10.1007/s10815-019-01609-4)

Samura O, Miharu N, He H, Okamoto E \& Ohama K 1997 Assessment of sex chromosome ratio and aneuploidy rate in motile spermatozoa selected by three different methods. Human Reproduction 12 2437-2442. (https://doi.org/10.1093/humrep/12.11.2437)

Sánchez-Castro M, Jiménez-Macedo AR, Sandalinas M \& Blanco J 2009 Prognostic value of sperm fluorescence in situ hybridization analysis over PGD. Human Reproduction 24 1516-1521. (https://doi.org/10.1093/ humrep/dep037)

Sarrate Z, Vidal F \& Blanco J 2010 Role of sperm fluorescent in situ hybridization studies in infertile patients: indications, study approach, and clinical relevance. Fertility and Sterility 93 1892-1902. (https://doi. org/10.1016/j.fertnstert.2008.12.139)

Shamonki MI, Jin H, Haimowitz Z \& Liu L 2016 Proof of concept: preimplantation genetic screening without embryo biopsy through analysis of cell-free DNA in spent embryo culture media. Fertility and Sterility 106 1312-1318. (https://doi.org/10.1016/j. fertnstert.2016.07.1112)

Silber S, Escudero T, Lenahan K, Abdelhadi I, Kilani Z \& Munné S 2003 Chromosomal abnormalities in embryos derived from testicular sperm extraction. Fertility and Sterility 79 30-38. (https://doi.org/10.1016/ s0015-0282(02)04407-2)

Soler A, Morales C, Mademont-Soler I, Margarit E, Borrell A, Borobio V, Muñoz M \& Sánchez A 2017 Overview of chromosome abnormalities in first trimester miscarriages: a series of 1,011 consecutive chorionic villi sample karyotypes. Cytogenetic and Genome Research 152 81-89. (https://doi.org/10.1159/000477707)

Somigliana E, Busnelli A, Paffoni A, Vigano P, Riccaboni A, Rubio C \& Capalbo A 2019 Cost-effectiveness of preimplantation genetic testing for aneuploidies. Fertility and Sterility 111 1169-1176. (https://doi. org/10.1016/j.fertnstert.2019.01.025)

Spinella F, Fiorentino F, Biricik A, Bono S, Ruberti A, Cotroneo E, Baldi M, Cursio E, Minasi MG \& Greco E 2018 Extent of chromosomal mosaicism influences the clinical outcome of in vitro fertilization treatments. Fertility and Sterility 109 77-83. (https://doi.org/10.1016/j. fertnstert.2017.09.025)

Sugiura-Ogasawara M, Ozaki Y, Katano K, Suzumori N, Kitaori T \& Mizutani E 2012 Abnormal embryonic karyotype is the most frequent cause of recurrent miscarriage. Human Reproduction 27 2297-2303. (https://doi.org/10.1093/humrep/des179)

Tang SS, Gao H, Robinson WP, Ho Yuen B \& Ma S 2004 An association between sex chromosomal aneuploidy in sperm and an abortus with $45, \mathrm{X}$ of paternal origin: possible transmission of chromosomal abnormalities through ICSI. Human Reproduction 19 147-151. (https:// doi.org/10.1093/humrep/deh007)
Tarozzi N, Nadalini M, Lagalla C, Coticchio G, Zacà C \& Borini A 2019 Male factor infertility impacts the rate of mosaic blastocysts in cycles of preimplantation genetic testing for aneuploidy. Journal of Assisted Reproduction and Genetics 36 2047-2055. (https://doi.org/10.1007/ s10815-019-01584-w)

Tempest HG, Homa ST, Dalakiouridou M, Christopikou D, Wright D, Zhai XP \& Griffin DK 2004 The association between male infertility and sperm disomy: evidence for variation in disomy levels among individuals and correlation between particular semen parameters and disomy of specific chromosome pairs. Reproductive Biology and Endocrinology 2 82. (https://doi.org/10.1186/1477-7827-2-82)

Treff NR, Su J, Tao X, Levy B \& Scott RT 2010 Accurate single cell 24 chromosome aneuploidy screening using whole genome amplification and single nucleotide polymorphism microarrays. Fertility and Sterility 94 2017-2021. (https://doi.org/10.1016/j.fertnstert. 2010.01.052)

Treff NR, Tao X, Ferry KM, Su J, Taylor D \& Scott RT 2012 Development and validation of an accurate quantitative real-time polymerase chain reaction-based assay for human blastocyst comprehensive chromosomal aneuploidy screening. Fertility and Sterility 97 819-824. (https://doi. org/10.1016/j.fertnstert.2012.01.115)

Ushijima C, Kumasako Y, Kihaile PE, Hirotsuru K \& Utsunomiya T 2000 Analysis of chromosomal abnormalities in human spermatozoa using multi-colour fluorescence in-situ hybridization. Human Reproduction 15 1107-1111. (https://doi.org/10.1093/humrep/15.5.1107)

Van Opstal D, Los FJ, Ramlakhan S, Van Hemel JO, Van Den Ouweland AM, Brandenburg H, Pieters MH, Verhoeff A, Vermeer MC, Dhont $M$ et al. 1997 Determination of the parent of origin in nine cases of prenatally detected chromosome aberrations found after intracytoplasmic sperm injection. Human Reproduction 12 682-686. (https://doi.org/10.1093/ humrep/12.4.682)

Vanneste E, Voet T, Le Caignec C, Ampe M, Konings P, Melotte C, Debrock S, Amyere M, Vikkula M, Schuit F et al. 2009 Chromosome instability is common in human cleavage-stage embryos. Nature Medicine 15 577-583. (https://doi.org/10.1038/ nm.1924)

Vendrell JM, García F, Veiga A, Calderón G, Egozcue S, Egozcue J \& Barri PN 1999 Meiotic abnormalities and spermatogenic parameters in severe oligoasthenozoospermia. Human Reproduction 14 375-378. (https://doi.org/10.1093/humrep/14.2.375)

Vera-Rodriguez $M$, Diez-Juan A, Jimenez-Almazan J, Martinez $S$, Navarro R, Peinado V, Mercader A, Meseguer M, Blesa D, Moreno I et al. 2018 Origin and composition of cell-free DNA in spent medium from human embryo culture during preimplantation development. Human Reproduction 33 745-756. (https://doi.org/10.1093/humrep/ dey028)

Vialard F, Hammoud I, Molina-Gomes D, Wainer R, Bergere M, Albert M, Bailly M, de Mazancourt P \& Selva J 2008 Gamete cytogenetic study in couples with implantation failure: aneuploidy rate is increased in both couple members. Journal of Assisted Reproduction and Genetics 25 539-545. (https://doi.org/10.1007/s10815008-9258-6)

Victor AR, Tyndall JC, Brake AJ, Lepkowsky LT, Murphy AE, Griffin DK, McCoy RC, Barnes FL, Zouves CG \& Viotti M 2019 One hundred mosaic embryos transferred prospectively in a single clinic: exploring when and why they result in healthy pregnancies. Fertility and Sterility 111 280-293. (https://doi.org/10.1016/j.fertnstert. 2018.10.019)

Wells D, Kaur K, Grifo J, Glassner M, Taylor JC, Fragouli E \& Munné S 2014 Clinical utilisation of a rapid low-pass whole genome sequencing technique for the diagnosis of aneuploidy in human embryos prior to implantation. Journal of Medical Genetics 51 553-562. (https://doi. org/10.1136/jmedgenet-2014-102497)

Xu J, Fang R, Chen L, Chen D, Xiao JP, Yang W, Wang H, Song X, Ma T, Bo $S$ et al. 2016 Non-invasive chromosome screening of human embryos by genome sequencing of embryo culture medium for in vitro fertilization. PNAS 113 11907-11912. (https://doi.org/10.1073/ pnas.1613294113)

Yeung QSY, Zhang YX, Chung JPW, Lui WT, Kwok YKY, Gui B, Kong GWS, Cao Y, Li TC \& Choy KW 2019 A prospective study of non-invasive preimplantation genetic testing for aneuploidies (NiPGT-A) using nextgeneration sequencing (NGS) on spent culture media (SCM). Journal 
of Assisted Reproduction and Genetics 36 1609-1621. (https://doi. org/10.1007/s10815-019-01517-7)

Zeyneloglu HB, Baltaci V, Ege S, Haberal A \& Batioglu S 2000 Detection of chromosomal abnormalities by fluorescent in-situ hybridization in immotile viable spermatozoa determined by hypo-osmotic sperm swelling test. Human Reproduction 15 853-856. (https://doi. org/10.1093/humrep/15.4.853)

Zielinska AP, Holubcova Z, Blayney M, Elder K \& Schuh M 2015 Sister kinetochore splitting and precocious disintegration of bivalents could explain the maternal age effect. eLife $\mathbf{4}$ e11389. (https://doi.org/10.7554/ eLife.11389)

Zielinska AP, Bellou E, Sharma N, Frombach AS, Seres KB, Gruhn JR, Blayney M, Eckel H, Moltrecht R, Elder K et al. 2019 Meiotic kinetochores fragment into multiple lobes upon cohesin loss in aging eggs. Current Biology 29 3749.e7-3765.e7. (https://doi.org/10.1016/j. cub.2019.09.006)

Received 19 January 2020

First decision 18 February 2020

Revised Manuscript received 14 August 2020

Accepted 7 September 2020 